\title{
DEPIRITISASI BATUBARA MENGGUNAKAN OKSIDATOR BESI (III) HASIL OLAHAN LIMBAH BESI
}

\section{COAL DEPYRITIZATION USING IRON (III) OXIDATOR FROM IRON SCRAP WASTE}

\author{
A. Sry Iryani ${ }^{* 1}$, Ismail Marzuki ${ }^{2}$ \\ *Email : andisryani@unifa.ac.id \\ 1,2 Prodi Teknik Kimia, Fak. Teknik' Universitas Fajar, \\ Jl. Prof. Abdurahman Basalamah No.101, Makassar
}

\begin{abstract}
ABSTRAK
Batubara merupakan bahan bakar fosil yang dapat dijadikan sebagai sumber bahan bakar alternatif pengganti bahan bakar minyak bumi dan gas alam yang sudah semakin menipis. Cadangan batubara di Indonesia, khususnya di Sulawesi cukup berpotensi, namun hingga saat ini belum dapat dimanfaatkan sebagai bahan bakar mengingat kandungan sulfurnya relatif tinggi yang dapat menyebabkan kerusakan pada alat pembakaran, dan dapat menimbulkan pencemaran lingkungan, kecuali terlebih dahulu dilakukan proses desulfurisasi sebelum pembakaran (precombustion). Penelitian ini bertujuan untuk mereduksi kandungan sulfur pirit dalam batubara sehingga memenuhi kriteria untuk dimanfaatkan sebagai salah satu bahan bakar industry. Secara khusus penelitian ini bertujuan untuk mempelajari mekanisme dan kinetika depiritsasi batubara menggunakan oksidator feri sulfat, sebagai usaha meminimalisasi kandungan sulfur batubara tersebut, maka dilakukan penelitian Desulfurisasi Batubara Menggunakan Oksidator Besi (III) Hasil Olahan Limbah Besi. Penelitian desulfurisasi batubara asal Mallawa (Sulawesi) skala laboratorium dilakukan dalam sebuah reaktor (labu leher empat) dengan sistem semi batch, dilengkapi dengan sebuah kompressor, flowmeter, termometer dan pengaduk. Karakterisasi, analisis proximate dan ultimate batubara dilakukan mengikuti prosedur ASTM Standar. Analisis sulfur total dilakukan dengan metode esckha yang dikombinasi dengan spektrofotometer $U V$, sedangkan nilai kalor batubara diukur dengan alat bomb kalorimeter. Dari hasil per hitungan diperoleh nilai orde reaksi $\mathrm{n}=1,771$. Nilai ini ternyata tidak bulat tetapi pecahan yang menunjukkan bahwa reaksi depiritisasi dengan pereaksi besi (III) sulfat merupakan reaksi kompleks yang terdiri dari beberapa tahap reaksi. Hasil penelitian ini diperoleh persamaan kinetika depiritisasi batubara dengan pereaksi besi (III) sulfat pada suhu $90{ }^{\circ} \mathrm{C}$, kecepatan pengadukan $930 \mathrm{rpm}$ sebagai berikut : $-\mathrm{rS}=6,741.10-2 . \mathrm{CS}(1,771)$
\end{abstract}

Kata kunci : Desulfurisasi, Batubara, Oksidator, Besi (III)

\begin{abstract}
Coal is a fossil fuel that can be used as an alternative fuel source fuel oil and natural gas that had been reduced. Coal reserves in Indonesia, especially in Sulawesi potent enough, but until now have not been utilized as fuel in view of the content of sulfur is relatively high which may cause damage to the appliance combustion, and can cause environmental pollution, except first performed desulfurization process prior to combustion (precombustion ). This study aims to reduce the sulfur content of pyrite in the coal so that it meets the criteria to be used as one of the fuel industry. Specifically, this research aims to study the mechanisms and kinetics of coal using an oxidizing ferry depiritsasi sulfate, in an effort to minimize the sulfur content of the coal, the Coal Desulfurization Using research conducted oxidizing iron (III) Processed Waste Iron. Research desulfurization of coal origin Mallawa (Sulawesi) was performed in a laboratory scale reactor (four-neck flask) with a semibatch system, equipped with a compressor, flowmeter, a thermometer and stirrer. Characterization, proximate and ultimate analysis of coal is done following the ASTM standard procedure. Total sulfur analysis was conducted using esckha combined with UV spectrophotometer, while the calorific value of coal was measured by a bomb calorimeter. From the results obtained value per count of the reaction order $n=1,771$. This value was not unanimous but a fraction indicating that the reaction reagent depiritisasi with iron (III) sulfate is a complex reaction that consists of several stages of reaction. The results of this study the kinetics equation obtained by reacting coal depiritisasi iron (III) sulphate at a temperature of $90^{\circ} \mathrm{C}$, stirring speed of $930 \mathrm{rpm}$ as follows: - $r S=6,741.10-2 . \mathrm{CS}$ $(1,771)$
\end{abstract}

Keywords : depyritisation,, coal, oxidizing, iron (III) 


\section{PENDAHULUAN}

Saat ini, Indonesia menghadapi permasalahan dalam penyediaan energi diakibatkan kebutuhan energi nasional yang besar dan meningkat setiap tahun. Sementara itu, cadangan minyak bumi dan produksi BBM Indonesia semakin terbatas, sehingga sejak beberapa tahun terakhir nilai impor minyak bumi dan BBM Indonesia semakin meningkat. Seiring cadangan sumber daya energi gas alam dan minyak bumi semakin menipis dan tingginya penggunaan serta pemanfaatan kedua sumber energi tersebut, maka dilakukan berbagai upaya untuk mencari sumber energi alternatif yang lebih ekonomis dan melimpah.

Sistem energi global menghadapi berbagai masalah di abad ini, harus terus memasok energi yang aman dan terjangkau untuk menghadapi kebutuhan yang terus tumbuh. Pada saat yang bersamaan masyarakat mengharapkan energi yang lebih bersih dan polusi yang rendah dengan meningkatkan penekanan pada ketahanan lingkungan hidup. Dalam waktu 30 tahun ke depan, diperkirakan bahwa kebutuhan energi global akan meningkat sebesar hampir 60\%. Dua pertiga dari kenaikan tersebut akan berasal dari negara-negara berkembang. Pada tahun 2030 negaranegara tersebut akan berjumlah hampir setengah dari seluruh kebutuhan energi.

Energi vital yang digunakan bagi pembangunan manusia, tidak mungkin menjalankan pabrik, menjalankan toko, menyerahkan barang ke konsumen atau bercocok tanam, misalnya tanpa adanya energi. Sebagai bahan bakar yang paling penting untuk membangkitkan listrik dan masukan vital dalam prouksi baja, batubara akan memainkan peran penting dalam memenuhi kebutuhan energi masa depan. Batubara akan terus memainkan peran vital dalam membangkitkan listrik dunia. Sementara batubara memasok 39\% dari listrik dunia, angka ini hanya akan turun satu angka persentase dalam waktu tiga dekade ke depan.

Batubara merupakan salah satu sumber daya alam yang berpotensi tinggi sebagai energi alternatif guna mencukupi kebutuhan energi non migas untuk industri, pembangkit tenaga listrik dan kebutuhan energi lainnya. Batubara memiliki nilai strategis dan potensial untuk memenuhi sebagian besar kebutuhan dalam negeri.

Untuk itu perlu adanya kegiatan eksplorasi dan pemanfaatan sumberdaya batubara demi kesejahteraan rakyat. Batubara merupakan bahan bakar alternatif dengan cadangan melimpah di Indonesia, khususnya di Sulawesi mengandung sulfur tinggi dalam hal ini pirit hingga mencapai 3\%. Kandungan sulfur tersebut dapat menyebabkan pencemaran lingkungan, menyebabkan kerusakan (korosif) dan memperpendek umur alat. Agar batubara tersebut dapat dimanfaatkan sebagai bahan bakar maka terlebih dahulu dilakukan proses desulfurisasi, dimana proses ini dapat dilakukan secara kimia yaitu dengan menggunakan oksidator besi (III) dari olahan limbah besi. Sebagaimana telah dilakukan penelitian sebelumnya (Aladin dkk, 2002) telah membuktikan bahwa reduksi sulfur anorganik (pirit) batubara dengan menggunakan oksidator besi (II), hanya saja dalam penelitian tersebut laju desulfurisasinya sangat lambat disebabkan dilakukan pada temperatur kamar.

Besi merupakan salah satu jenis limbah yang banyak dijumpai di industriindustri pengolahan logam, dimana limbah besi tersebut dapat diubah menjadi besi (II) dan selanjutnya dioksidasi menjadi besi (III) dengan menggunakan katalis $\mathrm{MnO}_{2}$ (Syarif, T, 2007) dan katalis batu apung (Aladin, dkk). Feri sulfat dapat dimanfaatkan antara lain sebagai koagulan dalam proses penjernihan air, bahkan efek koagulan feri sulfat 11 kali lebih besar dibandingkan fero sulfat (Ronnholm, dkk, 1999). Feri sulfat juga dapat dimanfaatkan sebagai bahan aditif semen pada industri beton, dan sebagai bahan pelapis pada pita video dan kaset. Elida Novita (2001) telah menggunakan feri 
sulfat untuk menurunkan nilai COD (Chemical Oxygen Demand) limbah cair pabrik tebu yang mengandung pigmen coklat gelap (melanoidin), sehingga besi (III) dapat digunakan sebagai oksidator dalam depiritisasi batubara (Aladin, dkk).

Berdasarkan uraian latar belakang di atas maka dirancang penelitian depiritisasi batubara secara kimia menggunakan oksidator feri sulfat hasil olahan limbah besi. Penelitian ini memiliki tujuan utama, yaitu mereduksi kandungan sulfur pirit dalam batubara sehingga memenuhi kriteria dimanfaatkan sebagai bahan bakar di industri. Secara khusus penelitian ini bertujuan mempelajari mekanisme dan kinetika depiritsasi batubara menggunakan oksidator feri sulfat berdasarkan pendekatan (asumsi) mekanisme reaksi homogen cair-cair.

\section{METODE PENELITIAN}

\section{Bahan}

Bahan utama pada penelitian ini berupa batubara asal daerah Mallawa (Sulawesi Selatan) dan oksidator besi (III) sulfat hasil olahan limbah besi, sedangkan larutan asam sulfat, $\mathrm{KMnO}_{4}$, Penantrolin, dan aquadest diperoleh dari Toko Bahan Kimia di kota Makassar.

\section{Peralatan}

Alat utama berupa reaktor yaitu berupa labu leher tiga yang dilengkapi pengaduk mekanik, pemanas mantel, pendingin balik, dan pengambil sampel serta kompressor udara dengan susunan rangkaian alat dibawah ini. Alat lainnya tersedia di laboratorium tempat penelitian ini berlangsung. Alat bantu terdiri dari seperangkat alat titrasi (statip, klem, buret), Spektro UV mini - 1240 Shimadzu, labu ukur, gelas ukur, erlenmeyer, timbangan, ayakan, corong dan botol sampel.

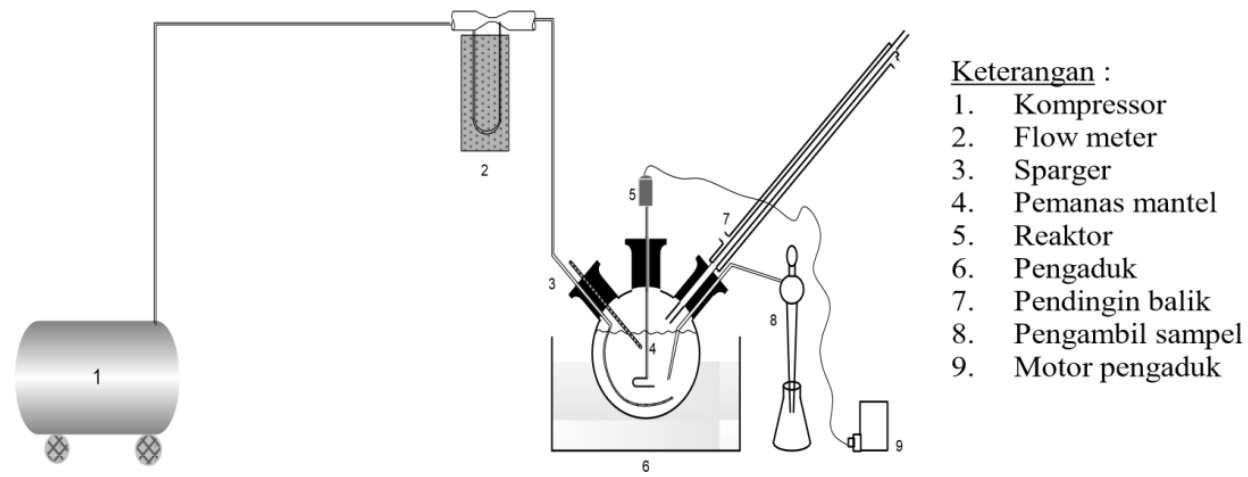

Gambar 1 : Rangkaian Peralatan

\section{Prosedur}

a. Pembuatan larutan fero sulfat, serbuk besi dilarutkan dengan asam sulfat di dalam labu leher tiga kemudian didiamkan dan disaring. Kandungan besi (II) dalam filtrat yang dihasilkan dianalisis dengan cara titrasi menggunakan larutan $\mathrm{KMnO}_{4} 0,1 \mathrm{~N}$. Titik akhir titrasi terjadi pada saat mulai terjadi perubahan warna menjadi warna merah jambu.

b. Pembuatan larutan feri sulfat, dengan mencampurkan larutan fero sulfat dengan asam sulfat di dalam labu leher tiga yang dilengkapi dengan pemanas dan 
pendingin balik. Selanjutnya larutan tersebut dipanaskan sambil di aduk dengan kecepatan $930 \mathrm{rpm}$ hingga mencapai temperature $90{ }^{\circ} \mathrm{C}$. Setelah mencapai temperatur konstan selama 100 menit, dilakukan pengambilan sampel sebanyak 5 $\mathrm{ml}$ untuk dilakukan analisis kandungan fero dan feri sulfatnya dengan cara titrasi menggunakan $\mathrm{KMnO}_{4} 0,1 \mathrm{~N}$.

c. Untuk preparasi dan karakteristik batubara serta desulfurisasi batubara dengan menggunakan oksidator besi (III) Sulfat. Sampel batubara pertama kali dilakukan peremukan dan penghalusan dengan cara crushing,grinding dan pengayakan hingga diperoleh batubara halus dengan ukuran 100 mesh dan dikarakterisasi meliputi: analisis proximate (kandung air, abu, zat terbang dan karbon tetap), analisis ultimate (komposisi $\mathrm{C}, \mathrm{H}, \mathrm{O}, \mathrm{N}, \mathrm{S}$ ), kandungan sulfur ( total, pirit,sulfat dan organic) dan nilai kalor dan bobot jenis dengan metode analisis mengikuti ASTM Standar.

d. Untuk proses depiritisasi batubara menggunakan oksidator Besi (III) Sulfat. Dengan mencampur sejumlah sample batubara $10 \mathrm{~g}$ dengan ukuran 100 mesh ditambahkan $25 \mathrm{ml} \mathrm{Fe} 2\left(\mathrm{SO}_{4}\right)_{3} 0,27 \mathrm{~N}$ kemudian dimasukkan ke dalam labu leher tiga dan di aduk dengan kecepatan $930 \mathrm{rpm}$ dan temperatur $90{ }^{\circ} \mathrm{C}$. Kemudian pengaduk dijalankan dan reaksi dimulai. Sampling dilakukan pada selang waktu tertentu. Kandungan besi (II) yang terbentuk dianalisis dengan spektro UV. Percobaan diulang untuk beberapa variasi waktu (t) : $0 ; 30 ; 45 ; 60 ; 75 ; 90 ; 120 ; 160 ; 180 ; 200$ menit

\section{HASIL DAN PEMBAHASAN}

\section{A. Karakterisasi Batubara}

Sampel batubara diambil langsung dari sumbernya yaitu di daerah Kecamatan Mallawa, Kabupaten Maros, Propinsi Sulawesi-Selatan. Analisis karakterisasi sampel batubara ini meliputi analisis proximate (moisture, volatile matter, ash dan fixed carbon), analisis ultimate (sulfur total) dan pengukuran nilai kalor dirangkum dalam Tabel 1 :

Tabel 1: Karakteristik Batubara Mallawa (Sulawesi-Selatan)

\begin{tabular}{cc}
\hline Parameter & Nilai \\
\hline 1. Sulfur-total (\%) & 3,30 \\
2. Sulfur-anorganik (\%) : & 2,44 \\
a. Sulfur-sulfat (\%) & 0,41 \\
b. Sulfur-pirit (\%) & 2,03 \\
3. Sulfur-organik (\%) & 0,86 \\
4. Zat terbang (\%) & 34,43 \\
5. Abu (\%) & 11,25 \\
6. Air lembab (\%) & 8,01 \\
7. Karbon tetap (\%) & 46,31 \\
8. Nilai Kalor (kkal/kg) & 5905 \\
\hline
\end{tabular}

Dari hasil analisis karakteristik batubara Mallawa di atas menunjukkan bahwa kualitas yang tidak jauh beda dengan hasil analisis batubara pada umumnya di Sulawesi Selatan oleh Dinas Pertambangan dan Energi Propinsi Sulawesi Selatan, demikian juga mirip dengan hasil karakterisasi dalam penelitian Hibah Pekerti (Aladin, dkk., 2005). Kandungan sulfur total batubara Mallawa sebesar 3,30 \% termasuk kategori tinggi yang belum memenuhi syarat dipergunakan sebagai bahan bakar di industri (maksimal 1\%) 
sebagaimana kriteria penggunaan batubara sebagai bahan bakar di industri semen dan PLTU.

Demikian pula kandungan abu batubara Mallawa sebesar $11,25 \%$ relatif tinggi, menurut kriteria Tabel 5 juga belum memenuhi syarat dipergunakan sebagai bahan bakar di industri (maksimal 10\%). Namun nilai kalor mencapai hampir $6000 \mathrm{kkal} / \mathrm{kg}$ maka batubara tersebut memungkinkan digunakan sebagai bahan bakar di Industri,

Berdasarkan karakteristik diatas, secara umum dapat dikatakan bahwa kriteria klasifikasi batubara menunjukkan bahwa batubara Mallawa termasuk kelas subituminous dengan kualitas tergolong relatif rendah yang belum memenuhi syarat untuk dimanfaatkan sebagai bahan bakar di industri khususnya di pabrik semen dan PLTU. Namun kualitas ini dapat ditingkatkan dengan cara desulfurisasi dan deashing, apalagi mengingat cadangan batubara di daerah tersebut cukup besar hampir mencapai 1 juta ton, juga mengingat telah berdiri industri besar pemakai bahan bakar batubara, yaitu industri PT. Semen Bosowa yang berdiri di daerah Maros dan PT Semen Tonasa yang berdiri di daerah Pangkep (Mandasini dan Aladin , 2003).

Secara spesifik terlihat bahwa kandungan sulfur batubara Mallawa lebih banyak berupa sulfur anorganik sebesar 2,44\% dari sulfur total $3,30 \%$ terutama dalam bentuk sulfur pirit $\left(\mathrm{FeS}_{2}\right)$ sebesar 2,03\%, dibanding dengan sulfur organik yaitu 0,86\%. Berdasarkan karakteristik ini yang dominan adalah sulfur pirit, maka dalam pemilihan teknik desulfurisasi sangat memungkinkan dan menguntungkan menggunakan teknik desulfurisasi secara oksidasi menggunkan oksidator besi (III)

(Aladin, 2002) .

\section{B. Penentuan Lamda Optimum dan Kurva Standar Spektrofotometer UV untuk Besi (II)}

\section{a. Penentuan $\lambda$ Optimum}

1. Pembuatan Larutan Induk Fe (II) 500 ppm.

Timbang dengan tepat (menggunakan timbangan elektrik) 0,2500 gram kristal $\mathrm{FeSO}_{4} .7 \mathrm{H}_{2} \mathrm{O}(\mathrm{BM}=278,0190 \mathrm{~g} / \mathrm{mol})$, kemudian dimasukkan ke dalam labu takar $500 \mathrm{ml}$. Dilarutkan dengan akuades secara bertahap hingga labu takar bersisi kira-kira 3/4 lalu dikocok (tidak langsung diisi penuh agar larutan mudah dikondisikan dan dikocok). Ditambahkan tiga tetes indikator fenantrolin $0,1 \mathrm{M}$ sambil dikocok dan $\mathrm{pH}$ diatur 5 - 6 . Ditambahkan lagi akuades dan dihimpitkan hingga tepat garis batas pada labu ukur $500 \mathrm{ml}$ tersebut, lalu dikocok sekali lagi dan didiamkan selama beberapa menit.

2. Pembuatan Larutan Dengan Variasi Konsentrasi.

Dari larutan blangko Fe (II) tersebut di atas dipipet $1 \mathrm{ml}$ dan diencerkan dengan akuades di dalam labu takar $50 \mathrm{ml}$ untuk mendapatkan larutan Fe (II) 10 ppm. Demikian juga dibuat variasi konsentrasi seperti table berikut untuk kebutuhan penentuan kurva standar larutan Fe (II).

\begin{tabular}{cccc}
\multicolumn{4}{c}{ Tabel $2:$ Pengenceran larutan Fe (II) dari larutan induk $500 \mathrm{ppm}$} \\
\hline $\mathrm{N} 1(\mathrm{ppm})$ & $\mathrm{V} 1(\mathrm{ml})$ & $\mathrm{V} 2(\mathrm{ml})$ & $\mathrm{N} 2(\mathrm{ppm})$ \\
\hline 500 & 7,000 & 50 & 70 \\
500 & 6,000 & 50 & 60 \\
500 & 5,000 & 50 & 50 \\
500 & 4,000 & 50 & 40 \\
500 & 3,000 & 50 & 30
\end{tabular}




\begin{tabular}{llll}
500 & 2,000 & 50 & 20 \\
500 & 1,000 & 50 & 10 \\
\hline
\end{tabular}

3. Penentuan $\lambda$ optimum $\mathrm{Fe}(\mathrm{II})$.

Larutan Fe (II) 40 ppm dimasukkan ke dalam kuvet sampai penuh untuk diukur serapannya pada berbagai panjang gelombang $(\lambda)$ dengan menggunakan alat spektrofotometer UV (type: Shimadzu Visible Spectrophotometer UVmini-1240V). Hasil pengukuran dirangkum dalam tabel berikut.

Tabel 3 : Serapan larutan Fe(II) pada berbagai panjang gelombang

\begin{tabular}{cccc}
\hline o. & $\lambda(\mathrm{nm})$ & Absorban & Kesimpulan \\
\hline 1 & 400 & 0,0873 & \\
2 & 410 & 0,0950 & Serapan max pada \\
3 & 420 & 0,1008 & $\lambda=510 \mathrm{~nm}$ \\
4 & 450 & 0,1107 & \\
5 & 470 & 0,1193 & \\
6 & 500 & 0,1241 & \\
$\mathbf{7}$ & $\mathbf{5 1 0}$ & $\mathbf{0 , 1 2 7 0}$ & \\
8 & 513 & 0,1265 & \\
9 & 515 & 0,1237 & \\
10 & 517 & 0,1227 & \\
11 & 520 & 0,1201 & \\
12 & 600 & 0,0449 & \\
\hline
\end{tabular}

Berdasarkan tabel pengukuran serapan di atas, dibuat grafik panjang gelombang versus serapan, diperoleh gambar 3. Dari grafik tersebut tampak bahwa serpan maksimum terjadi pada panjang gelombang 510, sehingga disimpulkan bahwa panjang gelombang optimum untuk larutan Fe (II) adalah 510.

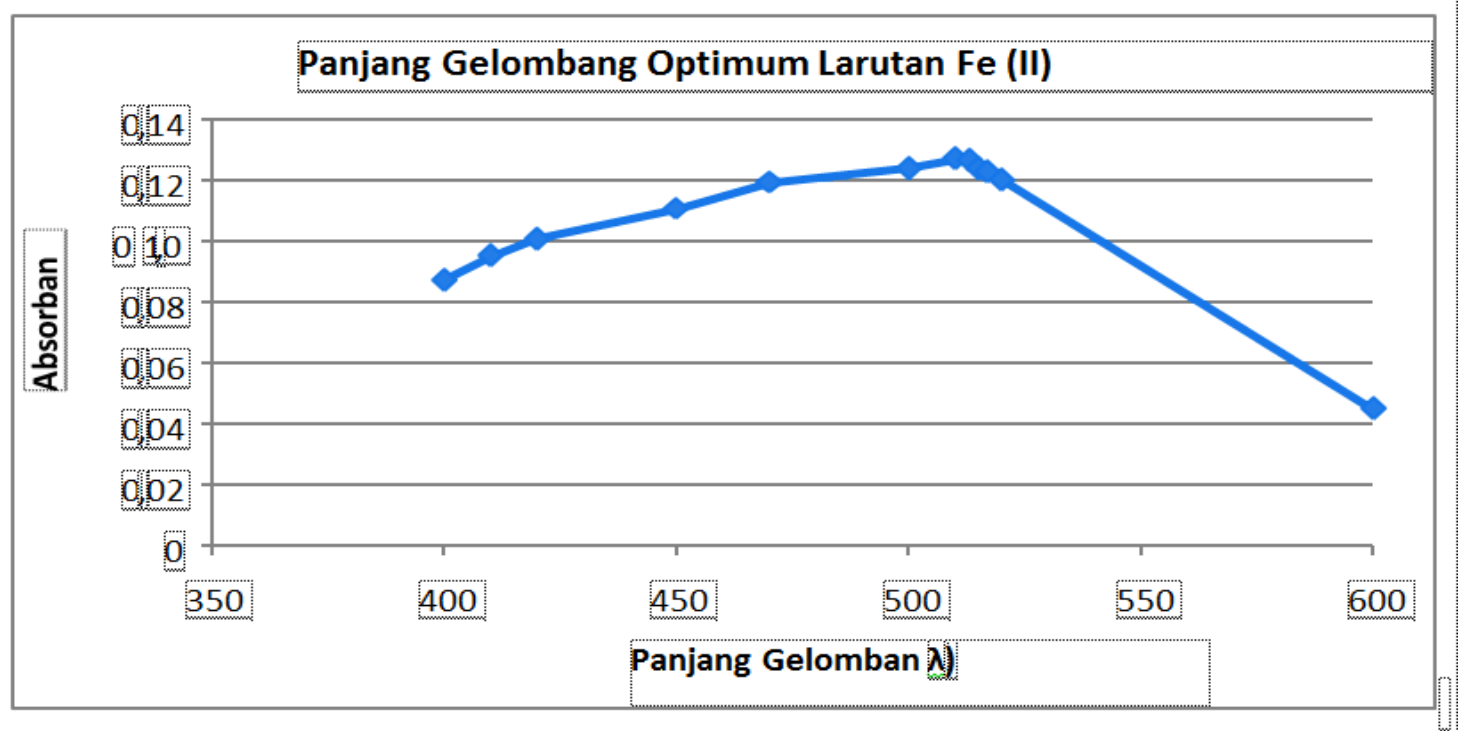

Gambar 2. Panjang Gelombang Optimum Larutan Fe (II) 


\section{b. Pembuatan kurva standar .}

Berdasarkan panjang gelombang optimum, dilakukan pengukuran serapan larutan besi (II) pada berbagai kosentrasi, hasil pengukuran dirangkum dalam tabel 4.

Tabel 4 : Serapan larutan besi (II) pada berbagai konsentrasi

\begin{tabular}{ccc}
\hline No & $\begin{array}{c}\text { Konsentrasi } \\
(\mathrm{ppm})\end{array}$ & Absorban \\
\hline 1 & 10 & 0,0874 \\
2 & 20 & 0,1036 \\
3 & 30 & 0,1127 \\
4 & 40 & 0,1344 \\
5 & 50 & 0,1404 \\
6 & 60 & 0,1591 \\
7 & 70 & 0,1716 \\
\hline
\end{tabular}

Berdasarkan data tabel 9 dibuat kurva standar (gambar 3), diperoleh persamaan standar untuk menghitung konsentrasi besi (II) (C; ppm) sebagai fungsi serapan, sebagai berikut: $\mathrm{C}=(\mathrm{A}-0,074) / 0,001$

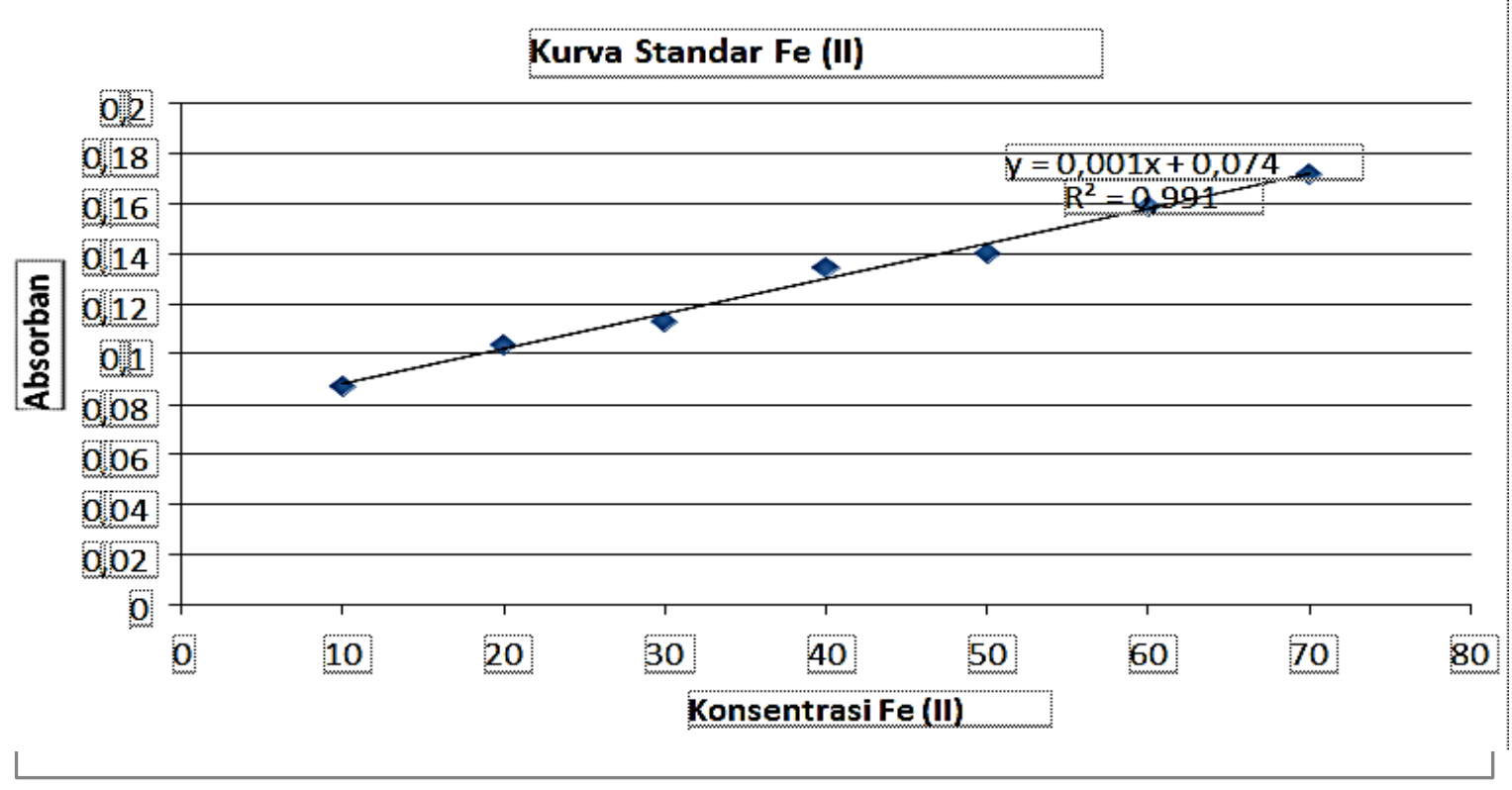

Gambar 3. Kurva Standar Larutan Besi (II) 


\section{Desulfurisasi Batubara Menggunakan Oksidator Besi (III) Sulfat}

Variasi waktu

Pengaruh waktu desulfurisasi batubara secara kimia menggunakan oksidator besi (III) sulfat dirangkum dalam tabel 5 dan gambar 4, berikut:

Tabel 5 : Pengaruh Waktu Desulfurisasi Batubara

\begin{tabular}{ccccccc}
\hline \multirow{2}{*}{ No } & \multirow{2}{*}{ (menit) } & Absorbansi & \multicolumn{2}{c}{$\mathrm{C}_{\mathrm{FeSO} 4}$} & \multirow{2}{*}{$\mathrm{C}_{\mathrm{FeS} 2}$} & \multirow{2}{*}{$\mathrm{CS}_{\mathrm{S}} \%$} \\
\cline { 4 - 5 } & & & $\mathrm{ppm}$ & $\mathrm{Mol} / \mathrm{L}$ & & \\
\hline 0 & 0 & 0 & 0,0079 & 2,03 & & \\
1 & 30 & 0,0768 & 139,65 & 0,0025 & 0,0054 & 1,39 \\
2 & 45 & 0,0780 & 201,06 & 0,0036 & 0,0043 & 1,10 \\
3 & 60 & 0,086 & 228,99 & 0,0041 & 0,0038 & 0,97 \\
4 & 75 & 0,0792 & 262,50 & 0,0047 & 0,0032 & 0,82 \\
5 & 90 & 0,0794 & 268,08 & 0,0048 & 0,0031 & 0,80 \\
6 & 120 & 0,080 & 301,59 & 0,0054 & 0,0025 & 0,64 \\
7 & 160 & 0,0807 & 335,10 & 0,0060 & 0,0019 & 0,49 \\
8 & 180 & 0,0809 & 346,27 & 0,0062 & 0,0017 & 0,45 \\
9 & 200 & 0,0810 & 351,86 & 0,0063 & 0,0016 & 0,41
\end{tabular}

Dari data di atas, dibuat grafik hubungan waktu reaksi dengan konsentrasi pirit sisa sebagai berikut :

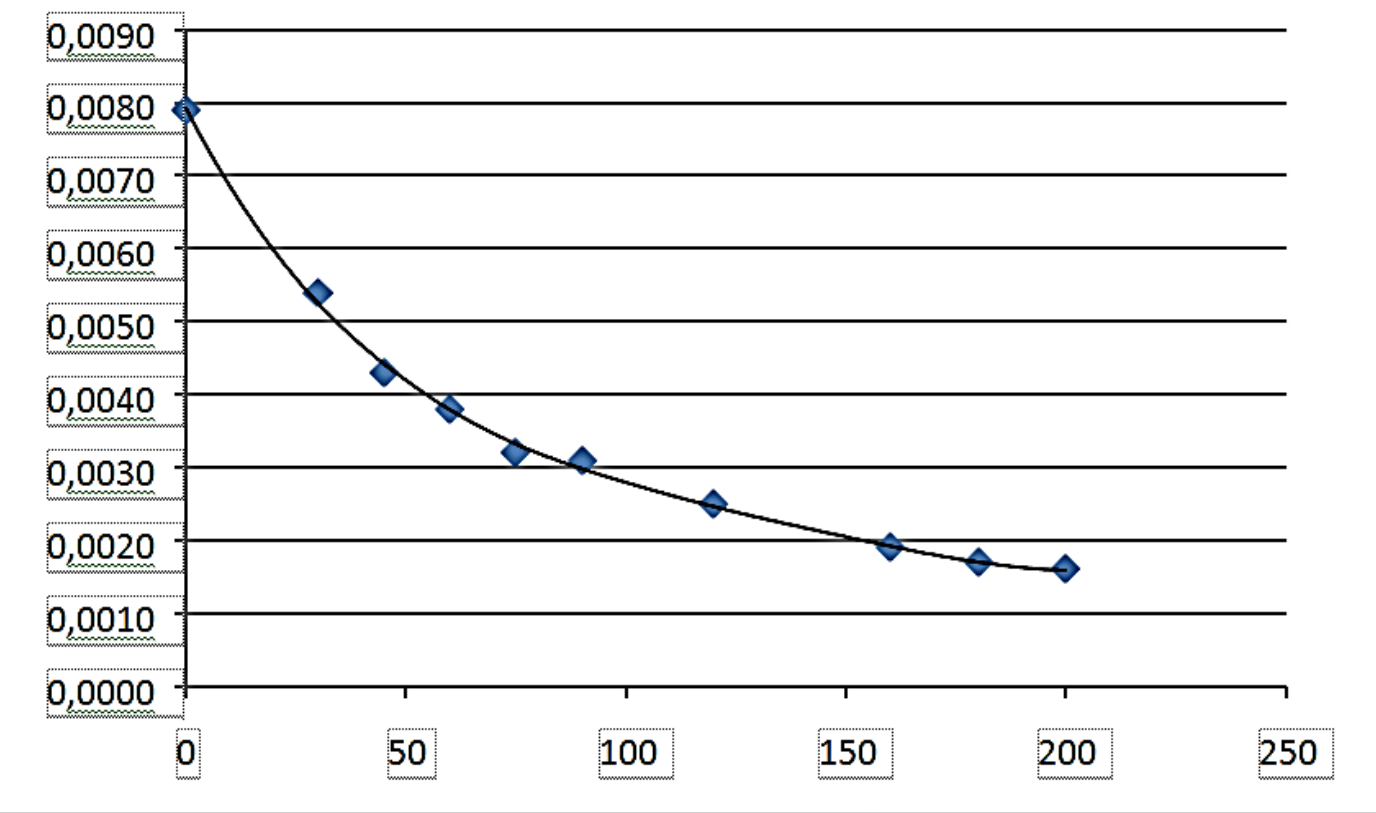

Gambar 4. Pengaruh waktu desulfurisasi batubara secara kimia menggunakan oksidator besi (III) sulfat 
Dari data dan grafik di atas, nampak terjadi depiritisasi secara siginifikan hingga waktu reaksi 160 menit (2,5 jam) dan laju depeiritisasi relative konstan sejak waktu 160 menit. Maka dengan demikian dapat disimpulkan bahwa waktu depiritisasi optimum adalah 160 menit yang memberikan sisa pirit minimum sebesar $0,009 \mathrm{~mol} / \mathrm{L}$ atau sisa sulfur minimum $0,49 \%$. Pengamatan variable rkasi selanjutnya didasarkan waktu optimum 160 menit. Berdasarkan data waktu reaksi dan konsetrasi pirit sisa di atas selanjutnya dilakukan olah data untuk mendapat orde dan kosntanta laju reaksi. Penentuan orde dan konstanta laju reaksi dengan metode integral seperti diuraikan dalam landasan teori. Hitungan dilakukan dengan bantuan program computer.

Dari hasil hitungan optimasi tersebut di atas diperoleh nilai orde reaksi $\mathrm{n}=$ 1,771. Nilai ini ternyata tidak bulat tetapi pecahan yang menunjukkan bahwa reaksi depiritisasi dengan pereaksi besi (III) sulfat merupakan reaksi kompleks yang terdiri dari beberapa tahap reaksi (Smith, 1983). Hal ini sesuai dengan landasan teori di atas, dimana reaksi depiritisasi disusun berdasarkan tiga tahap reaksi. Konstanta laju desulfurisasi $\mathrm{k}=6,741 \cdot 10^{-2} \mathrm{lt}^{0,771} \mathrm{~mol}^{-0,771}$ menit $^{-1}$. Nilai $\mathrm{k}$ ini relatif lebih besar $10 \mathrm{kali}$ lipat dari nilai $\mathrm{k}$ yang diperoleh oleh peneliti sebelumnya yaitu sebesar $\mathrm{k}=1,347965.10^{-}$ ${ }^{3} \mathrm{lt}^{0,695} \mathrm{~mol}^{-0,695}$ menit $^{-1}$ dengan orde reaksi $\mathrm{n}=1,695$ (Aladin $\mathrm{dkk}, 2002$ ).

Perbedaan nilai orde reaksi $\mathrm{n}$ dan konstanta laju $\mathrm{k}$ ini disebabkan perbedaan temperatur. Aladin dkk (2002) melakukan penelitian desulfurisasi pada temparatur kamar $\left(25{ }^{\circ} \mathrm{C}\right)$ sedangkan pada penelitian dilakukan pada temperature $\left.90{ }^{\circ} \mathrm{C}\right)$. Meningkatnya nilai $\mathrm{k}$ ini dapat dipahami dengan meningkatnya temparatur reaksi, sebab menurut Archennus konstanta k merupakan fungsi temparatur ( $\mathrm{k}=\mathrm{A} \cdot \exp [-\mathrm{E} / \mathrm{RT}]$ ), dimana laju reaksi akan meningkat hingga dua kali setiap kenaikan temparatur $10{ }^{\circ} \mathrm{C}$ (Johnstone and Thring, 1957 ).

Faktor penyebab lainnya adalah adanya perbedaan konsentrasi pereaksi oksigen, dimana pada penelitian sengaja dibuat berlebih dengan cara mengalirkan udara dengan alat compressor pada laju alir udara 2 liter/menit. Aliran udara masuk reaktor ini menyebabkan automixing (pengadukan) disamping pengadukan dengan alat pengaduk pada putaran $930 \mathrm{rpm}$. Adanya pengadukan ekstra ini merupakan factor lain penyebab meningkatnya laju reaksi, sebab pengadukan yang tinggi memberikan naiknya factor tumbukan (A) dalam persamaan Archenus di atas. Hasil penelitian ini diperoleh persamaan kinetika depiritisasi batubara dengan pereaksi besi (III) sulfat pada suhu 90 ${ }^{\circ} \mathrm{C}$, kecepatan pengadukan $930 \mathrm{rpm}$ sebagai berikut: $-\mathrm{rS}=6,741 \cdot 10-2 . \mathrm{CS}(1,771)$

\section{PENUTUP}

\section{Kesimpulan} berikut :

Berdasarkan hasil penelitian dan pembahasan, dapat ditarik kesimpulan sebagai

1. Dari penelitian ini diperoleh hasil karakterisasi batubara Mallawa (sebelum desulfurisasi) yaitu kadar sulfur total 3,28\%, kadar abu 11,25\%, zat terbang $34,43 \%$, kadar air 8,01\%, karbon tetap 46,31\% dan nilai kalor 5,905 kal/kg. Jenis sulfur terdiri atas sulfur anorganik 2,42\% (berupa sulfur pirit 2,01\% dan sulfur sulfat $0,41 \%$ ) dan sisanya sulfur organik $0,86 \%$. Berdasarkan karakteristik ini menunjukkan bahwa batubara Mallawa termasuk kelas subtuminous, suatu jenis batubara dengan kualitas tergolong relatif rendah dengan kandungan sulfur dan abu relatif tinggi.

2. Kondisi-kondisi optimum (terbaik) desulfurisasi batubara secara kimia menggunakan oksidator besi (III) hasil olahan limbah besi (pada kondisi aliran udara dan ukuran batubara dibuat tetap masing-masing 2 liter per menit dan 100 
mesh, yaitu topt $=120$ menit, Topt $=90^{\circ} \mathrm{C}$, dan Nopt $=930 \mathrm{rpm}$, dengan persen recovery maksimum sebesar

$76,46 \%$.

\section{Referensi}

Aladin, A., Takdir Syarif., Lastri W., dan Rismawati R., 2010, “Pengolahan Serbuk Limbah Besi Menjadi Besi (III): Tinjauan Kinetika Model Quasi Steady State “, Jurnal Reaktor, Vol. 13 No.2, Desember 2010, hal. 74-80.

Aladin, A., 2002, "Batubara Asal Sulawesi Antara Peluang dan Tantangan “, Jurnal Teknologi \& Industri FAQIH, FTI-UMI Makassar Vol. 1, No. 2, hal. 95-98.

Aladin, A., Henny, A., dan Wiwin, S., 2002, "Studi Kinetika Desulfurisasi Batubara Menggunakan Besi(III) Sulfat Pada Temprature Kamar", Prosiding Seminar Nasional Teknologi Proses Kimia, 2002, UI Jakarta.

Aladin, A., Takdir Syarif., Rismawati., Asmuliyani, “ Pemanfaatan Limbah Besi Dalam Penanganan Limbah Sulfur Batubara “, Laporan Hibah Bersaing 2009.

Aladin, A., Sumber Daya Alam Batubara”, 2011

Celik, M.S. and Yildirim, I., 2000, "A New Physical Process For Desulfurization of Low-Rank Coals" Journal of FUEL, Volume 79, Issue 13, October 2000, pp. 1665-1669.

Demirbas, 2002, "Demineralization and Desulphurization of Coals via Column Froth Flotation and Different Methods", Journal of Energy Conversion \& Management, Vol. 43, pp. 885-895.

Mukherjee, S. and Borthakur, P. C., 2001 "Chemical Demineralization / Desulfurization Of High Sulphur Coal Using Sodium Hydoroxyde And Acid Solutions" Journal of FUEL, Vol. 80, pp. 2037-2040.

Mukherjee, S. and Borthakur, P. C., 2004 "Demineralization of Subbituminous High Sulphur Coal Using Mineral Acids" Journal of Fuel Processing Technology, Volume 85, Issues 2-3, 15 February 2004, pp. 157-164.

Novita, E., 2001, "Optimasi Proses Koagulasi Flokulasi pada Limbah Cair yang Mengandung Melanoidin", Jurnal Ilmu Dasar, Vol-2, No. 1,61 - 67.

Roesyadi, A. dan Aladin, A. 2005, "Karakterisasi, Desulfurisasi Dan

Deashing Batubara Asal Sulawesi Secara Flotasi”, Jurnal MEDIA TEKNIK edisi Februari 2005, Fak. Teknik UGM Yogyakarta

Ronnholm, M.R., Warna, J., Salmi, T., Turunen, I., Luoma, M, 1999, "Oxidation Kinetics of Ferrous Sulfate over Active Carbon", Ind. Eng. Chem. Res., 38, 2607 - 2614.

Syarif, T., 2007, Oksidasi Katalitik Fero Sulfat Menjadi Feri Sulfat Dengan Katalis MnO2, Disertasi S2 Teknik Kimia UGM Yogyakarta.

Syarif, T., 2007, "Pengaruh Kecepatan Putaran Pengaduk dan Laju Alir Udara Pada Proses Oksidasi Katalitik Fero Sulfat Menjadi Feri Sulfat", Jurnal Teknologi \& Industri FAQIH, Vol. 7, No.14

Setiyawati Yani., 2010, “ Sulphur Transformation During Pyrolisis of an Australian Lignite”, Journal Coumbust Institute,

Setiyawati Yani., 2010, “Fuel Pyrite”, Vol. 89, ISSN 0016 - 2361 Journal Coumbust Institute, 